\title{
Reseñas
}

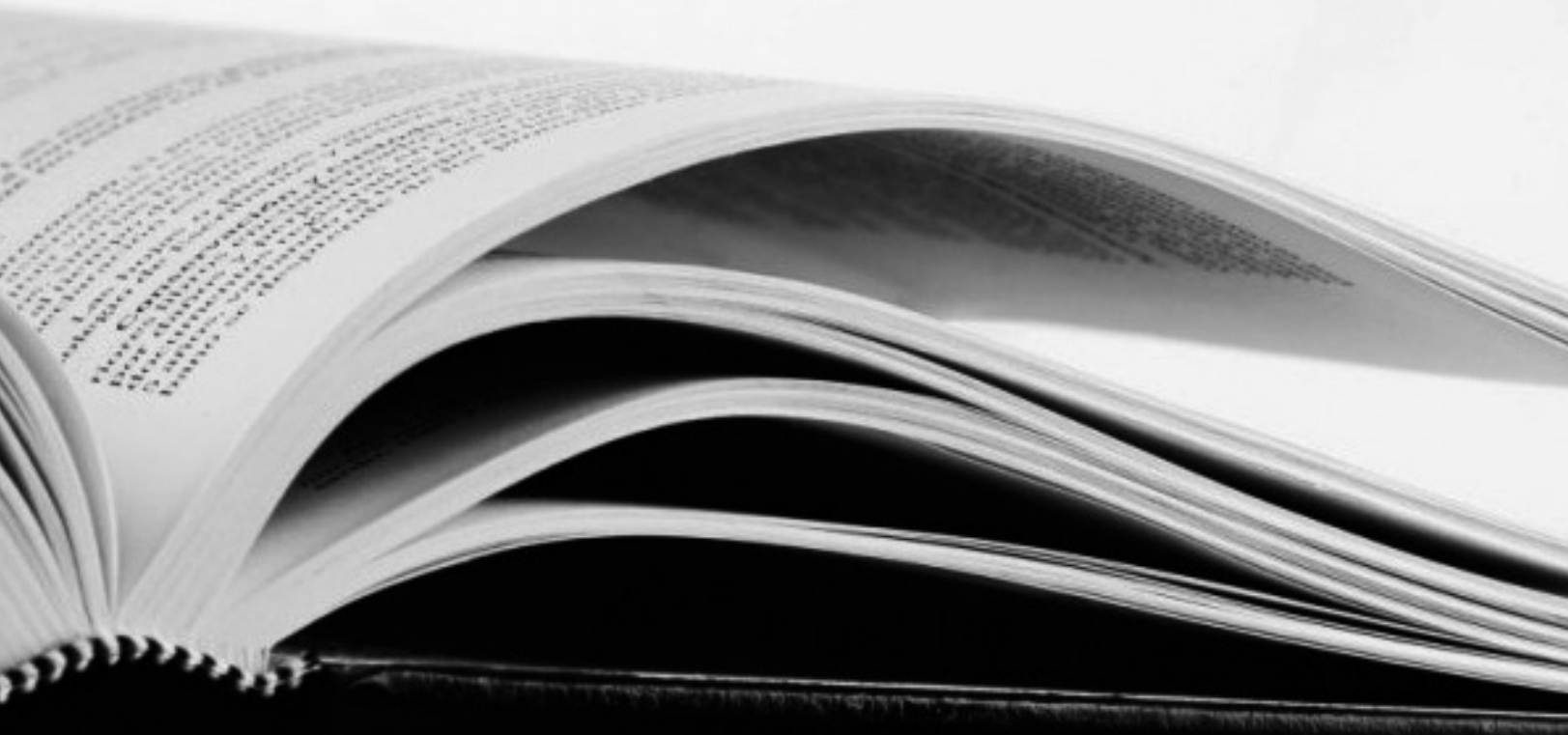



Universidad de Guadalajara

Derecho Global. Estudios sobre Derecho y Justicia Año 2021, Vol. VI. Número 17, Marzo - Junio, pp 197-205, ISSN: 2448-5128 e-ISSN: 2448-5136 https://DOI.org/10.32870/dgedj.v6i17.367

JOSÉ ENRIQUE CONDE BELMONTE Universidad Alfonso x el Sabio, España jcondbel@uax.es

\section{El Ombudsman de la vivienda en México. INSTITUCIÓN JURÍDICA EN POR DE LA IGUALDAD Y LA DIGNIDAD HUMANA}


La obra titulada El Ombudsman de la Vivienda en México. Institución jurídica en pro de la igualdad y la dignidad humana tiene su génesis en las postrimerías de la década de los noventa, cuando su autor, el Dr. José Alberto del Rivero del Rivero, inició una ardua investigación sobre el derecho a la vivienda en México, publicando en el diario El Día en 1998 un análisis sobre la equidad constitucional aplicable a la problemática de los deudores hipotecarios, y trasladando esta cavilación a la Cámara de Diputados en el año de 1999 en aras de exponer las bondades del texto constitucional mexicano en relación a la defensa de los deudores en contra del anatocismo. Más tarde, en 2010, como resultado de una investigación más profunda, el Dr. Del Rivero publicó su libro La vivienda como derecho constitucional, en el cual hace importantes aportaciones sobre la previsión constitucional de este derecho en México, proponiendo así una reforma al artículo $4^{\circ}$ de la Constitución Política de los Estados Unidos Mexicanos (CPEUM). Todo ello lo condujo a continuar estudiando la injusticiabilidad de la vivienda en el sistema jurídico mexicano, publicando en el año de 2018 la obra que motiva esta sucinta reseña, pero esta vez con una propuesta innovadora para crear una institución encargada de proteger el derecho humano a la vivienda a partir del ejemplo de otras naciones en el tema de la defensa sectorial de los derechos humanos.

Sin temor a errar, la vivienda significa para los seres humanos uno de los aspectos más intrínsecos a su supervivencia en el mundo. Es innato a todo ser vivo y animado resguardarse de los peligros que representan otras especies e incluso el propio entorno natural. Ya desde los antecesores del homo sapiens existía este instinto por tener un sitio seguro para su propia tranquilidad, que hoy en la contemporaneidad se ha perpetuado en lo que conocemos como una vivienda, pero lamentablemente cada país le otorga el cariz de esencialidad dependiendo de sus designios internos. Sabemos que el derecho humano a la vivienda actualmente representa un elemento base sobre el cual se realizan a su vez otros derechos. En realidad, inclusive la vida misma de las personas depende de la garantía que se le conceda al derecho humano a la vivienda. De este discernimiento, el profesor Del Rivero zarpa con su tratado sobre la vivienda adecuada, enarbolándolo con una cita del Tribunal Europeo de Derechos Humanos al señalar que "Un Estado 
que no garantice viviendas seguras se debe considerar responsable de no proteger el derecho a la vida".

En este libro se parte de un análisis filosófico aplicado a la consignación del derecho a la vivienda en el artículo $4^{\circ}$ de la CPEUM, en el que se le atribuye a la vivienda la cualidad de digna. Al respecto, se discurre una argumentación basada en antecedentes clásicos y contemporáneos para comprender que la dignidad es un atributo que solo corresponde al ser humano, mas no a los objetos como lo es una vivienda. Como propuesta de reforma al texto constitucional, se consideran instrumentos internacionales (del sistema universal e interamericano) que reconocen el derecho humano a la vivienda adecuada (no digna, ni decorosa). Esta expresión es crucial debido a que en la Observación General No. 4 del Comité de Derechos Económicos Sociales y Culturales (Comité DESC) se señalan específicamente cuáles son los elementos de una vivienda adecuada (pp. $56,131,199,252$ y 401):

1. Seguridad jurídica de la tenencia.

2. Disponibilidad de servicios, materiales e infraestructura.

3. Gastos soportables.

4. Habitabilidad.

5. Asequibilidad.

6. Ubicación.

7. Adecuación cultural.

Los citados elementos son de suma importancia para la realización integral del derecho humano a la vivienda adecuada dado que como se reflexiona a lo largo de esta obra, este derecho no debe ser entendido solo como el permitir que una persona acceda a tener un simple techo, sino que tiene todo un bagaje aún más amplio. Con ello entendemos que una vivienda para ser adecuada debe brindar a sus habitantes la certeza suficiente de que nadie los desalojará de una forma ilegítima (seguridad jurídica de la tenencia); debe contar con servicios vitales para nuestra existencia y desarrollo relacionados a la salud, seguridad, higiene, comodidad y nutrición (disponibilidad de servicios, materiales e infraestructura); 
los gastos personales o del hogar no deben comprometer la satisfacción de necesidades básicas (gastos soportables de manutención); una vivienda debe tener un espacio adecuado para sus habitantes y protegerlos de las inclemencias (habitabilidad); significa el acceso pleno y sostenible a los recursos adecuados para obtener una vivienda por parte de los grupos en situación de desventaja (asequibilidad); la vivienda debe encontrarse en un sitio que permita el acceso a opciones de trabajo, servicios de salud, de educación, entre otros (ubicación adecuada); y el método y los materiales para su construcción, las políticas en que estos se apoyan, así como la modernización deben permitir la expresión de la identidad cultural y la diversidad, además de que los servicios tecnológicos estén presentes sin sacrificar dimensiones culturales de la vivienda (adecuación cultural).

El Dr. Del Rivero hace notar que la vivienda adecuada no se encuentra garantizada en México debido al desconocimiento de los aspectos que esta implica, aunado a la falta de acciones, verbi gratia: 1) que los sectores público y privado sean incapaces de satisfacer el acceso a este derecho; 2) la insuficiencia económica de las personas y los altos intereses de la banca; 3) la necesidad de tener que asentarse en predios de bajo costo sin importar sus condiciones (p. 121); y 4) la inadecuación de la vivienda para ciertas personas, como por ejemplo, small people (personas pequeñas), personas de la tercera edad, así como personas con diversidad funcional (p. 133).

Como agravante del contexto que embarga la garantía del derecho humano a la vivienda en México, yace otro hecho que causa preocupación para la justiciabilidad del mismo (es decir, la posibilidad de reclamar la reivindicación de este derecho a través de mecanismos jurídicos). Antes debe recordarse que el Pacto Internacional de los Derechos Económicos Sociales y Culturales (PIDESC), adoptado por la comunidad internacional en el año de 1966, al que México se adhirió hasta 1981, que reconoce en su artículo 11 el derecho humano a la vivienda adecuada (p. 116), fue el que originó a su vez otro destacable instrumento de vinculación internacional al cual México no se ha adherido aún. Nos referimos al Protocolo Facultativo del PIDESC, adoptado en 2008 por la Asamblea General de las Naciones Unidas. Este instrumento hace que los derechos reconocidos en el PIDESC puedan ser reivindicados ante eventuales transgresiones por parte

\section{2}


de los Estados Partes, en el entendido de que aquel Estado que no sea parte del Protocolo Facultativo no puede ser señalado por alguna violación de derechos económicos, sociales y culturales ante el Comité DESC. Por este motivo, si un derecho humano de segunda generación es violentado dentro de la nación mexicana, las personas no pueden recurrir ante el Comité DESC (pp. 147-155). Así, la justiciabilidad ya en concreto de la vivienda adecuada se ve mermada por la falta de una garantía para reclamar eventuales incumplimientos con los aspectos que la componen.

Abundando en el tema de la justiciabilidad de la vivienda adecuada en México, el profesor Del Rivero enfatiza que en la esfera interna no se tiene mejor suerte que en la internacional debido a que los mecanismos jurisdiccionales y los no jurisdiccionales, no brindan una protección focalizada en este derecho. Al respecto, en su libro se trae a la luz una interrogante sobre la protección de los derechos de segunda generación: si los derechos civiles son protegidos por el juicio de amparo; y los derechos políticos, por el juicio para la protección de los derechos político-electorales, ¿qué mecanismo protege a los derechos económicos, sociales y culturales en donde se encuentra el derecho a la vivienda adecuada? (p. 282). Con independencia de esto, también destaca que el Poder Judicial de la Federación ha venido asentando trascendentales criterios en relación a la exigibilidad del derecho a la vivienda adecuada desde una perspectiva de eficacia horizontal, que abarca a particulares y autoridades (pp. 275-277), pero esto aún no se ha visto reflejado en la normatividad constitucional, en la que persiste la confusión aterrante de atribuir dignidad y decoro a este derecho.

Sobre los mecanismos no jurisdiccionales de derechos humanos (comisiones nacional y estatales de derechos humanos), en esta obra se reflexiona que su enfoque es restrictivo, al solo centrarse en las violaciones que ocurren en el ámbito de la vivienda social, teniendo como protagonistas a las autoridades que integran los fondos de vivienda social, asimismo se resalta la falta de promoción de este derecho de cara a la población en México (pp. 294-309). Sumándose está el hecho de que, por su naturaleza así concebida en el sistema jurídico mexicano, las comisiones de derechos humanos no pueden intervenir cuando exista un acto de un particular (por ejemplo, una empresa inmobiliaria) que merme alguno de los elementos de la vivienda adecuada, como ocurre en otras naciones, pues 
la figura del ombudsman no solo fue ideada para atender quejas en contra de autoridades, sino también entre particulares.

Al sensibilizarse sobre estos puntos, el Dr. Del Rivero propone la posibilidad de que en el sistema jurídico mexicano se prevea, a la par de las comisiones de derechos humanos, un mecanismo de protección no jurisdiccional y sectorial para la defensa concretamente del derecho humano a la vivienda adecuada, como parte de la garantía que debe existir en la eventual reforma al artículo $4^{\circ}$ de la CPEUM. Al leer el texto constitucional, nos topamos con la vaguedad de que "La Ley establecerá los instrumentos y apoyos necesarios a fin de alcanzar tal objetivo", ¿por qué no mejor establecer directamente cuál será el mecanismo de justiciabilidad que velará por el cumplimiento de este derecho? En efecto, esta ha sido una interrogante que ha subrayado el autor de este libro desde antaño. En su propuesta, él denomina a esta institución el "Ombudsman de la Vivienda", proposición que tiene su basamento en los paradigmas de otros países, como Reino Unido, en donde existe la figura del Housing Ombudsman, que no solamente se dedica a las violaciones que se configuran en el ámbito público, sino primordialmente en el contexto de particulares, en otras palabras, en el día a día de la vida de las personas.

En su tratado sobre el Ombudsman de la Vivienda en México, el Dr. Del Rivero se adentra en el origen de la protección sectorial de los derechos humanos y cómo diferentes países en Europa y también en América han ido adoptado este tipo de figuras que se dedican a la defensa de un derecho humano en específico, y que además tienen la posibilidad, en algunos casos, de intervenir en las transgresiones que se susciten entre particulares. Amén de estos ejemplos, se ilustra al lector con diversos antecedentes de este tipo de protección sectorial que incluso han existido durante la historia del país mexicano antes y después de su independencia.

Es importante resaltar que en esta obra no se propone la desaparición de los actuales mecanismos de protección "general" de los derechos humanos, refiriéndonos a las comisiones, sino que la figura de un Ombudsman de la Vivienda puede aunar y apuntalar la realización de un derecho que aún continúa pendiente en la agenda de justiciabilidad de México, y que en lugar de contar con un mecanismo de garantía, tal como lo indica el profesor Del Rivero en su libro, la vivienda ha pasado a ser la panacea electoral de los programas sociales. 


\section{Bibliografía}

Libro: $\quad$ El Ombudsman de la Vivienda en México. Institución jurídica en pro de la igualdad y la dignidad humana.

Autor: José Alberto del Rivero del Rivero

Editorial: Beg Institute - Berg Oceana Aufklarung

Lugar: España

Año: 2018

Páginas: 484

Cómo citar el artículo: Conde J, (2021). Reseña: El Ombudsman de la Vivienda en México. Institución jurídica en pro de la igualdad y la dignidad humana. Derecho Global, Estudios sobre Derecho y Justicia, VI (17) pp. 209-215 https://DOI.org/10.32870/dgedj.v6i17.367 